\title{
Optimization of Residential Load Consumption during Energy Peaks using Smart Metering
}

\author{
Rovan Refaat El-Razky ${ }^{1}$, Ahmed Ali Daoud ${ }^{2}$, Kamel El-serafi ${ }^{3}$ \\ Department of Electrical Engineering, Faculty of Engineering, Port Said University, Egypt \\ Rovan.refaat@yahoo.com, ahmed.ali.daoud@gmail.com, relserafi@hotmail.com
}

\begin{abstract}
Recently smart demand side management (DSM) is a very important tool that permits customers to take right decisions for their energy consumption and helps the energy utilities to decrease the over load demand and reshape the load curve.

This paper proposes an optimized DSM technique based on smart metering uses different techniques such as load shifting and peak clipping to minimize domestic power consumption especially during load peaks. A new optimization technique (Bat Algorithm) is applied on proposed system and then compares results with other optimization techniques (Genetic Algorithm and Interior point Algorithm) to optimize the minimum consumption during peak hours according to load type. A control algorithm is applied to the proposed system to achieve the load shifting and load clipping according to the optimization results.
\end{abstract}

\section{Keywords}

Demand Side Management, Smart metering, Genetic Algorithm, Bat Algorithm.

\section{INTRODUCTION}

Smart grid is a power grid based on smart control using smart meters and technologies with two-way digital communication between grid parts. This new technique provided allows for monitoring, analysis and control to reduce energy consumption and cost, increase reliability of the supply, finally improve the grid efficiency $[1,2]$.

Demand side management (DSM) is the amendment for consumer demand for energy by encourages the consumer to use less energy during peak hours or to move the time of energy use to off-peak times. DSM is reliable and costeffective tool that manages the demand according to power generated from supply so it is a serious for load management in smart grid, therefore DSM reshape load curve for energy consumption and reduce the overall peak load demand and the overall cost, the energy efficiency will enhance and make the operating cost of utility less [3].

Smart pricing is a smart tool to encourage users to save energy consumption by using smart metering devices. DSM system will cognize group's central controller about new load schedule and loads that can be reduced for each time step, control center can place bids in the market such that some loads from the peak demand will be shifted or shed. Profits made through this load DSM will be paid back for customers of the group $[4,5]$.

In this paper a DSM mechanism is proposed classing loads to three classes according to consumers' life style then using smart meters and controllers to manage load curves thereafter applying three different optimization algorithms and comparing algorithms results to take a smart control action to eliminate consumption during peaks and minimize consumer bill according to smart pricing calculations.

\section{ENERGY CONTROL IN SMART GRID}

\section{a) Smart grid model}

Modern power grid is a complex network consisting of power plants, transmission lines, substations, distribution grids and consumers $[6,7]$.

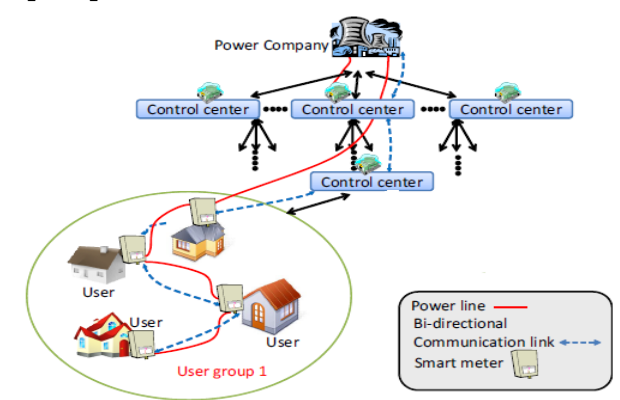

Fig.1. smart grid system architecture [8]

Figure (1) shows main component of smart grid which is divided to three layers beginning with power generation which came from power company then control center where optimization process performed finally user side which include energy distribution gird and measure energy consumption using smart meter. Smart meter is a very important function used as each smart meter can scheduling the energy consumption of the end user and communicating control centers [8]. 


\section{b) DSM techniques}

Demand side management uses planning, implementation and evaluation of programs to save the energy consumption utilizing without reducing service quality [12].

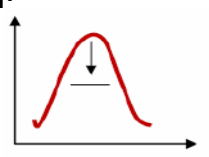

Peak Clipping

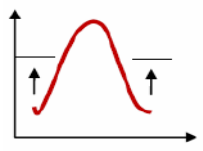

Valley Filling

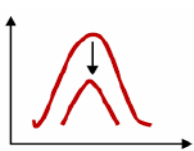

Conservation

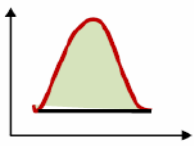

Flexible Load Shape

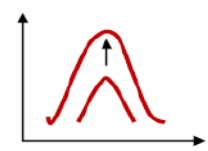

Load Building

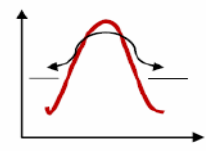

Load Shifting
Fig.2. Different Demand Side Management Methods [13]

Figure (2) shows the different DSM techniques, Peak clipping (PC), valley filling (VF), load shifting (LS), and flexible load shape (FLS), represent objectives to change energy consumption at specific times. Four objectives can be affected in operational timeframes through utility load management. Strategic conservation (SC) and strategic load growth (SLG), represent objectives to decrease or increase load at levels remaining effective in the long run $[1,13]$.

\section{PROPOSED SMART DSM}

\section{a) Customer Control}

Customer control side consists of two main parts: control center, smart meter [9]. A programmable logic controller (PLC) is used as a control center which implements the proposed algorithm and provides an interface between the appliances, sensors, and the controller [10].

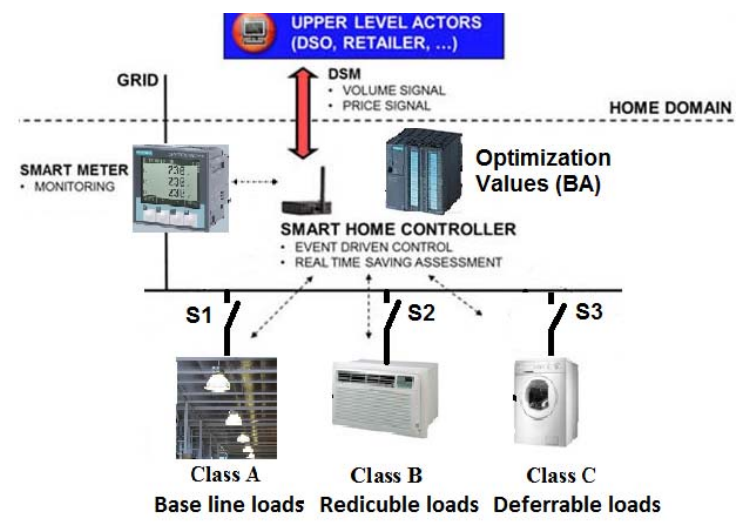

Fig.3. Structure of the proposed system

Figure (3) shows the proposed smart home controller and Illustrates the used PLC in proposed algorithm, the used smart meter is a control panel tool for measuring current, power, etc. [11]. Finally three classes of appliances are proposed algorithm.

\section{b) DSM Strategy}

In this paper, it is proposed generalized daily load consumption for residential load and applied DSM strategy using optimization algorithm. The first DSM technique is load shifting that can be applied by the central controller according to DSM targets.
The proposed algorithm is applied in three different optimization methods (interior point, genetic algorithm, and bat algorithm) to find out the best daily load curve.

\section{I) Problem Formulation}

Every user aims at minimization of total cost of electricity consumption, represented by the following objective function $[8,14]$.

$$
\begin{gathered}
\text { Minimize: } E C=\sum_{i=1}^{n} P_{i} * E_{i} \\
P i=C E i \log (E i+1)
\end{gathered}
$$

Subject to:

$$
\beta-\alpha_{a} \geq 0
$$

Where,

EC: Electricity cost during a day.

$\mathrm{P}_{\mathrm{i}}$ : Energy price in hour $\mathrm{i}$, where

$\mathrm{E}_{\mathrm{i}}$ : Total Energy consumption in hour i, where Pi proportional to data for feeder (voltage, phase angle, the cost of transmission and distribution).

C: price parameter, calculated using Egyptian Electric utility and Consumer Protection in table (III) as a guide.

Price parameter in this paper is varied in different periods around 24 hours as the first period (8AM: 2PM and 2AM: 8AM are OFF Peak periods with $\mathrm{C}$ parameter) and (2PM: $8 \mathrm{PM}$ and 8 PM: $2 \mathrm{AM}$ are Over Peak periods with another $\mathrm{C}$ parameter) applied monthly tariff as an hourly tariff with results scaled [8]. $\mathrm{Ei}=$ Power consumption by consumer - Total Power shed from each consumer.

$\beta=\mathrm{P}_{\mathrm{u}} / \mathrm{P}_{\mathrm{a}}$ utility to load power ratio.

$\alpha_{\mathrm{a}}=\mathrm{P}_{\mathrm{ai}} / \mathrm{P}_{\mathrm{a}}$ area load ratio.

$\mathrm{P}_{\mathrm{u}}$ : The power from utility.

$\mathrm{P}_{\mathrm{ai}}$ : The current load power in area a, at time $\mathrm{i}$.

$\mathrm{P}_{\mathrm{a}}$ : The connected load power in area $\mathrm{a}$.

If, $\mathrm{Pu}<\mathrm{Pa}$ and $\beta<\alpha_{\mathrm{a}}$, Then amount of load to $\mathrm{b}$ shed is given by:

$$
P_{1} \text {, shed }=\left(\alpha_{a}-\beta\right) * P_{a}
$$

Subjected to:

$$
\begin{gathered}
\mathrm{P}_{\text {min }}<\mathrm{Pl} \text {, shed }<\mathrm{P}_{\text {max }} \\
\text { Ei }<\text { Feeder load power }
\end{gathered}
$$

The optimization method must get the optimum value for power consumption after shed the power from each consumer using one of the ways of optimization (genetic algorithm, interior point solver, bat-inspired algorithm).

\section{II) DSM Proposed Algorithm}

In this paper, a demand side management strategy is proposed for smart grid is based on load shifting technique then using load shedding for emergency cases, handling a number of devices of load types.

Proposed algorithm has flexibility in constructing and developing the algorithm, in this paper three different algorithms are used to reach to the best method of optimization to get minimum cost with best load curve. This algorithm allows implementation of features that model load demand based on the lifestyles of the customers so that the disturbance to the customers can be minimized. 


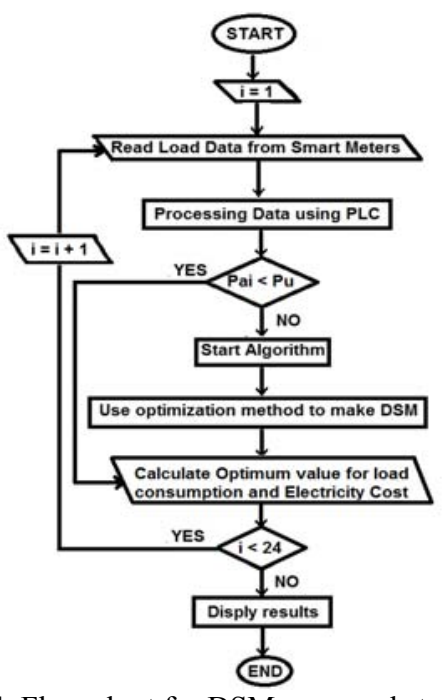

Fig.4. Flow chart for DSM proposed strategy

\section{APPLICATION OF PROPOSED SMART}

\section{DSM}

We categorize loads into three types: A- Base line loads whose power consumption must be continuous for all the time, such as lightning, refrigerator and fans, B- reducible loads, whose power consumption can be decreased for some time periods, such as air conditioning and Water heater, Cdeferrable loads, whose operation or charging time can be deferred, such as washing machines, Electrical oven and Microwave oven [17].

Table (I): Daily load consumption for consumer (1):

\begin{tabular}{|c|c|c|c|c|c|}
\hline Time & $\begin{array}{c}\text { Class } \\
\text { A }\end{array}$ & $\begin{array}{c}\text { Class } \\
\text { B }\end{array}$ & $\begin{array}{c}\text { Class } \\
\text { C }\end{array}$ & $\begin{array}{c}\text { Total power } \\
\text { consumption }\end{array}$ & $\begin{array}{c}\text { Total cost } \\
\text { before } \\
\text { optimization }\end{array}$ \\
\hline $8 \mathrm{am}$ & 455 & 500 & 1100 & 2055 & 0.77317 \\
\hline 9am & 455 & 510 & 0 & 965 & 0.1728 \\
\hline $10 \mathrm{am}$ & 455 & 10 & 250 & 715 & 0.0904 \\
\hline $11 \mathrm{am}$ & 455 & 1010 & 0 & 1465 & 0.3755 \\
\hline $12 \mathrm{pm}$ & 455 & 1010 & 0 & 1465 & 0.3755 \\
\hline $1 \mathrm{pm}$ & 455 & 1010 & 0 & 1465 & 0.3755 \\
\hline $2 \mathrm{pm}$ & 455 & 1500 & 310 & 2265 & 1.07 \\
\hline $3 \mathrm{pm}$ & 455 & 1500 & 1060 & 3015 & 1.966 \\
\hline $4 \mathrm{pm}$ & 470 & 1000 & 110 & 1580 & 0.4965 \\
\hline $5 \mathrm{pm}$ & 470 & 1010 & 10 & 1490 & 0.438 \\
\hline $6 \mathrm{pm}$ & 470 & 1010 & 10 & 1490 & 0.438 \\
\hline $7 \mathrm{pm}$ & 490 & 10 & 1460 & 1960 & 0.78634 \\
\hline $8 \mathrm{pm}$ & 490 & 510 & 810 & 1810 & 0.6635 \\
\hline 9pm & 490 & 510 & 1060 & 2060 & 0.8743 \\
\hline $10 \mathrm{pm}$ & 490 & 10 & 360 & 860 & 0.15 \\
\hline $11 \mathrm{pm}$ & 490 & 10 & 250 & 750 & 0.11173 \\
\hline $12 \mathrm{am}$ & 490 & 10 & 250 & 750 & 0.1117 \\
\hline $1 \mathrm{am}$ & 340 & 10 & 100 & 450 & 0.48265 \\
\hline 2am & 320 & 0 & 0 & 320 & 0.2305 \\
\hline 3am & 300 & 0 & 0 & 300 & 0.2 \\
\hline 4am & 300 & 0 & 0 & 300 & 0.2 \\
\hline $5 \mathrm{am}$ & 300 & 0 & 0 & 300 & 0.2 \\
\hline $6 \mathrm{am}$ & 300 & 500 & 0 & 800 & 0.1155 \\
\hline $7 \mathrm{am}$ & 300 & 500 & 0 & 800 & 0.1155 \\
\hline maximum & 490 & 1500 & 1460 & 3015 & 10.81312 \\
\hline load & & & & & \\
\hline & & & & & \\
\hline
\end{tabular}

In order to simulate real life consumption with accessible data, we used an Egyptian daily load consumption designated for one consumer. Table (I) shows daily load consumption for Egyptian customer with base line loads, reducible loads "according to usage" and deferrable loads.
The system consists of utility and distribution system, IEEE4 node test feeder on one hand and test consumer (1) on the other hand [15].

Table (II): Loads are connected in grounded wye for four wire line configurations [15].

\begin{tabular}{|c|c|c|}
\hline & Balanced & Unbalanced \\
\hline Phase-1 (kW) & 1200 & 850 \\
\hline Power Factor & 0.9 lag & $0.85 \mathrm{lag}$ \\
\hline Phase-2(kW) & 1200 & 1200 \\
\hline Power Factor & $0.9 \mathrm{lag}$ & $0.9 \mathrm{lag}$ \\
\hline Phase-3 $(\mathrm{kW})$ & 1200 & 1583.33 \\
\hline Power Factor & $0.9 \mathrm{lag}$ & $0.95 \mathrm{lag}$ \\
\hline
\end{tabular}

As transformer must be loaded with $80 \%$; So Maximum power consumption is $1200 \mathrm{KW} * 80 \%=960 \mathrm{KW}$ according to load data in Table (II), If we have 400 consumer \& so power consumption for one consumer $=960 \mathrm{KW} / 400$ consumer $=$ 2400Watt. Making optimization will be for consumer which power consumption more than 2400Watt.

Table (III): Gives the tariff according to Egyptian utility divided into consumption category [16]:

\begin{tabular}{|c|c|}
\hline $\begin{array}{c}\text { Power consumption } \\
\text { (KWH/month) }\end{array}$ & $\begin{array}{c}\text { Price2016/2017 } \\
\text { (piaster/consumer-month) }\end{array}$ \\
\hline Up to 50 & 10 \\
\hline $51-100$ & 19 \\
\hline $0-200$ & 26 \\
\hline $201-350$ & 35 \\
\hline $351-650$ & 44 \\
\hline $651-1000$ & 71 \\
\hline More than 1000 & 81 \\
\hline
\end{tabular}

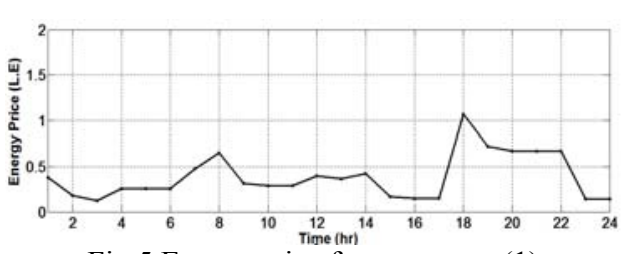

Fig.5 Energy price for consumer (1)

Figure 5 show the energy price values after price parameter is calculated according to applied table (III) as an hourly tariff with results scaled and table (I) in equation (2) [8].

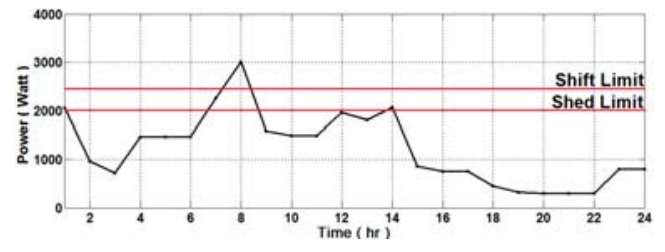

Fig.6.a. power comsumption for consumer (1)

From figure 6.a. it can be noted that loads at $2 \mathrm{pm}$ and $3 \mathrm{pm}$ are more than 2000 watt on the other hand loads form $10 \mathrm{pm}$ to $8 \mathrm{am}$ are less than 1000 watt, so when optimization is taken place the points of high loads must be shifted to points where loads are low.

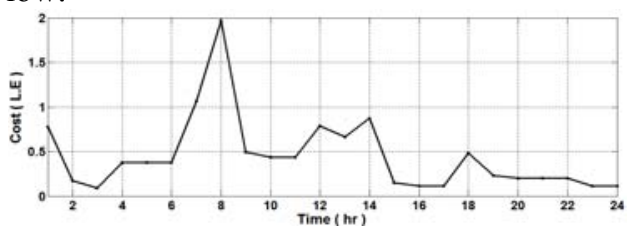

Fig.6.b. cost before optimization

Figure 6.b gives the daily cost for typical customer according to Table III, average cost before optimization $=10.8$ L.E/day. 


\section{COST OPTIMIZATION AND SMART DSM}

\section{(I) Interior Point optimization method}

Interior point method is an optimization technique used to shift the load consumption from the peak hours to off-peak hours.

Interior point methods are algorithms that solve linear and nonlinear convex optimization problems and achieve optimization by going through the middle of the solid [18].

The objective function will be

Where,

$$
\text { Minimize cost }=\sum_{i=1}^{n} E_{i}\left(\sum_{t=1}^{24} X_{i t} \cdot \text { Cost }_{t}\right)
$$

$\mathrm{n}$ : appliances in a smart home that were scheduled in $\mathrm{t}$ time.

$\mathrm{E}_{\mathrm{i}}$ : energy consumed by appliances.

$X_{i j}$ : an indicator variable.

Cost $_{\mathrm{j}}$ : is a constant function that reflects the cost of power consumption at a time $t$, calculated by equation (2).

Subject to:

$\sum_{\mathrm{i}=1}^{\mathrm{n}} \mathrm{E}_{\mathrm{i}} \mathrm{X}_{\mathrm{ij}} \leq$ the maximum power capacity in time $\mathrm{t}$ $\mathrm{X}_{\mathrm{ij}}=1$ (if the appliance is on), $\mathrm{X}_{\mathrm{ij}}=0$ (if the appliance is off) Matlab - Simulink software is used to simulate the proposed DSM

\section{1) Load shifting:}

Applying interior point optimization method the load peaks which must be shifted was around from $2 \mathrm{pm}$ to $2 \mathrm{am}$ so $8.33 \%$ of loads during peaks must be shifted then we have the resulting load curve of figure 7.a.

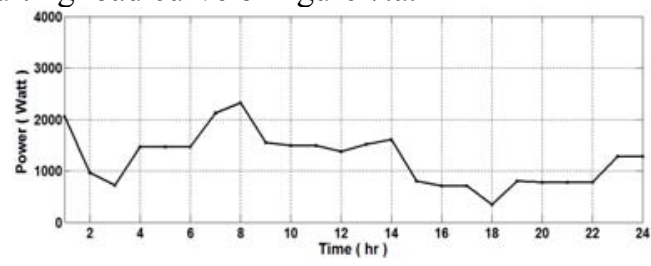

Fig.7.a. load curve after optimization

In Figure 7.a, it can be noted that the value of maximum power consumption according to load data table and getting number of consumer fed from this node; points where load is higher than the value of power consumption will be determined for each hour.

The power will be shifted from 2 pm to 8 am to add 482 watt to each hour, maximum power consumption will reduce from 3015 watt to 2326 watt at 2 am and load curve will be smoother than load curve before optimization.

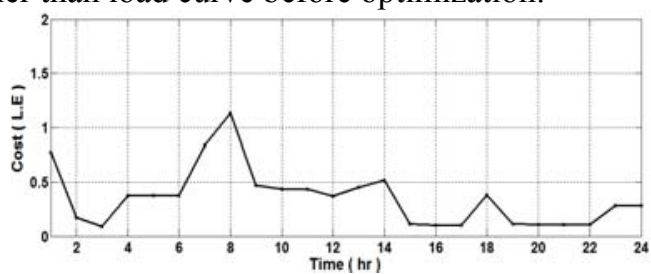

Fig.7.b. cost after optimization

From Figure 7.b, Total cost after load shifting $=8.528$ L.E/day, the value of total cost will be $78.7 \%$ from the first value.

\section{2) Load shedding:}

After Appling optimization to shift the load peaks there will be some of load peaks more than 1990 watt (maximum base line and reducible loads) and they must be shedding as load at $8 \mathrm{am}, 2 \mathrm{pm}$ and $3 \mathrm{pm}$ so $3.7 \%$ of loads during these times must be shed.

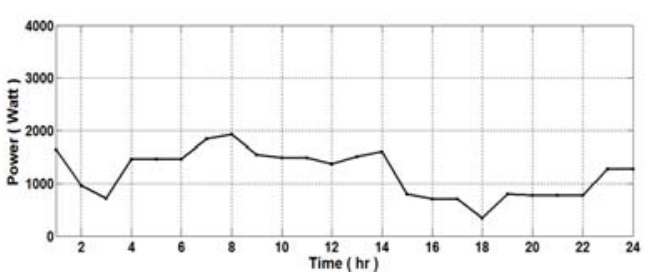

Fig.8. load curve after optimization

In Figure 8, sometimes load consumption at peaks must be shed to make safety operation to substation devices so the nodes where loads are high will be shed using optimization method. Total power shedding after optimization=1087.2 Watt.

Total load consumption after load shedding $=28784 \mathrm{WH}$, Maximum power consumption will reduce from 2326 watt to 1923.8 watt at 2 am and load curve will be more smooth than load curve before optimization, So the reduction in power consumption using linear programming is around $2.2 \%$ of total power consumption per day. Total cost after load shedding $=$ 7.713 L.E/day.

\section{(II) Genetic Algorithm}

In order to compare results and find the best optimization method we use different techniques called Genetic algorithm and Bat algorithm $[19,22]$.

$$
\begin{gathered}
f_{i}=f_{i}^{\text {min }}+\left[\left(f_{i}^{\text {max }}-f_{i}^{\text {min }}\right) D V\left(x_{i}\right) /\left(2^{A i}-1\right)\right] \\
A i=\log _{2}\left[\left(f_{i}^{\max }-f_{i}^{\text {min }}\right) / \epsilon_{i}\right.
\end{gathered}
$$

$\operatorname{DV}\left(\mathrm{x}_{\mathrm{i}}\right)$ : is decoded value of string, the decoded value of a binary substring $\mathrm{x} \equiv\left(\mathrm{x}_{\mathrm{A}-1} \mathrm{x}_{\mathrm{A}-2} \ldots \mathrm{x}_{2} \mathrm{x}_{1} \mathrm{x}_{0}\right)$ is calculated as $\Sigma_{\mathrm{j}=0}^{\mathrm{A}-1} 2^{\mathrm{j}} \mathrm{x}_{\mathrm{j}}$, where $\mathrm{x} \in\{0,1\}$.

$\mathrm{Ai}$ : the length of substring, the total string length of a Nvariable solution is then $\mathrm{A}=\Sigma^{\mathrm{N}}{ }_{\mathrm{i}=1} \mathrm{Ai}$

$\epsilon_{\mathrm{i}}$ : the parameter which is desired precision in $\mathrm{i}$ th variable.

\section{1) Load shifting:}

After using optimization the load peaks which must be shifted was around from $2 \mathrm{pm}$ to 2 am so $9.27 \%$ of loads during peaks must be shifted.

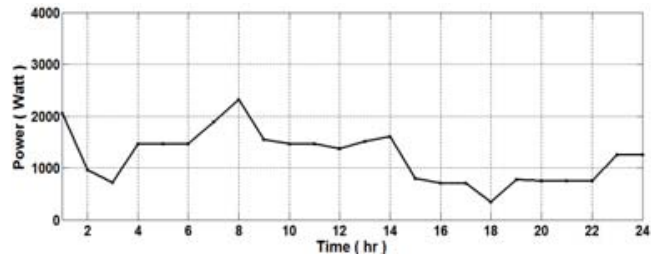

Fig.9.a. load curve after optimization

In Figure 9.a, it can be noted that the value of maximum power consumption according to load data table and getting number of consumer fed from this node; points where load is higher than the value of power consumption will be determined for each hour. The power will be shifted from $2 \mathrm{pm}$ to $8 \mathrm{am}$ to add 454.7watt to each hour.

Maximum power consumption will reduce from 3015 watt to 2318.4 watt at 2 am and load curve will be smoother than load curve before optimization.

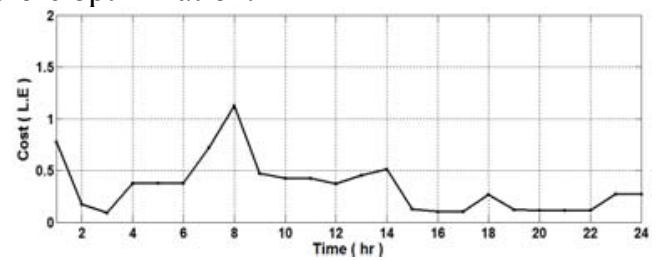

Fig.9.b. cost after optimization

From Figure 9.b, total cost after load shifting $=8.266$ L.E/day. 


\section{2) Load shedding:}

After using optimization to shift the load peaks there will be some of load peaks more than 1955 watt and they must be shedding as load at $8 \mathrm{am}$ and $3 \mathrm{pm}$ so $2.6 \%$ of loads during these times must be shed.

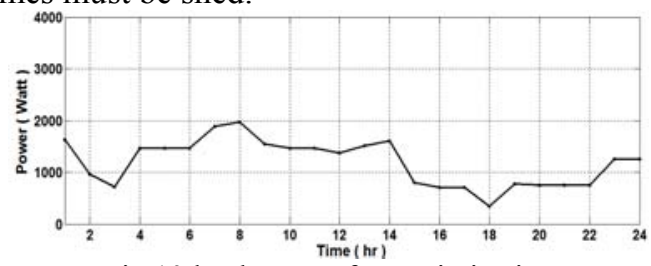

Fig.10 load curve after optimization

In Figure 10, sometimes load consumption at peaks must be shed to make safety operation to substation devices so the nodes where loads are high will be shed using optimization method, total power shedding after optimization=769 Watt, total load consumption after load shedding $=28661 \mathrm{WH}$.

Maximum power consumption will reduce from 2318.4 watt to 1968.4 watt at 2 am and load curve will be smoother than load curve before optimization, so the reduction in power consumption using GA is around $2.6 \%$ of total power consumption per day. Total cost after load shedding $=7.63$ L.E/day.

\section{(III) Bat Algorithm}

The Bat Algorithm (BA) based on the phenomenon of echolocation bat, these bats can find insects and discriminate different types of them in full darkness. New studies indicate that this algorithm is very grater (Yang 2010) [20, 21].

In simulations, virtual bats naturally are used. Ei (Total Energy consumption in hour $\mathrm{t}$ ) are their positions and $\mathrm{Pi}$ (Energy price in hour $\mathrm{t}$ ) is their speeds in a d-dimensional space are updated. The new solution $\mathrm{E}_{\mathrm{i}}^{\mathrm{t}}$ and speed $\mathrm{P}_{\mathrm{i}}^{\mathrm{t}}$ at time $\mathrm{t}$ are given by

$$
\begin{gathered}
\mathrm{EC}_{\mathrm{i}}=\mathrm{EC}_{\min }+\left(\mathrm{EC}_{\max }-\mathrm{EC}_{\min }\right) \beta \\
\mathrm{P}_{\mathrm{i}}^{\mathrm{t}}=\mathrm{P}_{\mathrm{i}}^{\mathrm{t}-1}+\left(\mathrm{E}_{\mathrm{i}}^{\mathrm{t}}-\mathrm{E}_{*}\right) \mathrm{EC}_{\mathrm{i}} \\
\mathrm{E}_{\mathrm{i}}^{\mathrm{t}}=\mathrm{E}_{\mathrm{i}}^{\mathrm{t}-1}+\mathrm{P}_{\mathrm{i}}^{\mathrm{t}}
\end{gathered}
$$

Where,

$\beta \epsilon[0,1]$ is a random vector derived from a regular distribution. $\mathrm{E}_{*}$ is the best present solution that is found after comparing all solutions.

$$
\mathrm{Enew}_{\mathrm{n}}=\mathrm{E} \text { old }+\mathrm{CA}
$$

$\mathrm{EC}[-1,1]$ is a random number.

$\mathrm{A}^{\mathrm{t}}=\left\langle\mathrm{A}_{\mathrm{i}}^{\mathrm{t}}\right\rangle$ is the average loudness of all the bats at this time step.

\section{1) Load shifting:}

After using optimization the load peaks which must be shifted was around from $2 \mathrm{pm}$ to 2 am so $9.94 \%$ of loads during peaks must be shifted.

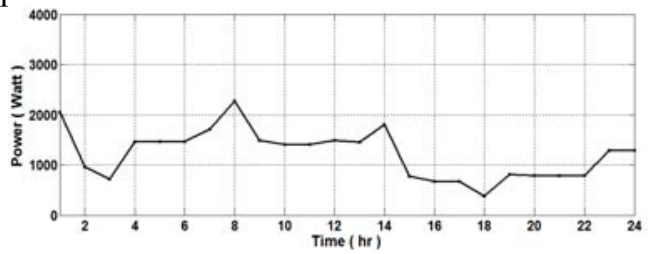

Fig.11.a. load curve after optimization

In Figure 11.a, it can be noted that the value of maximum power consumption according to load data table and getting number of consumer fed from this node; points where load is higher than the value of power consumption will be determined for each hours.
The power will be shifted from 2 pm to 8 am to add 487.35 watt to each hour.

Maximum power consumption will reduce from 3015 watt to 2271 watt at 2 am and load curve will be smoother than load curve before optimization.

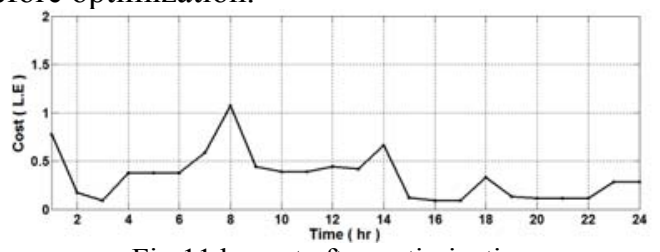

Fig.11.b. cost after optimization

From Figure 11.b, total cost after load shifting $=8.23$ L.E/day

\section{2) Load shedding:}

After using optimization to shift the load peaks there will be some of load peaks more than 1955watt and they must be shedding as load at $8 \mathrm{am}$ and $3 \mathrm{pm}$ so $2.8 \%$ of loads during these times must be shed.

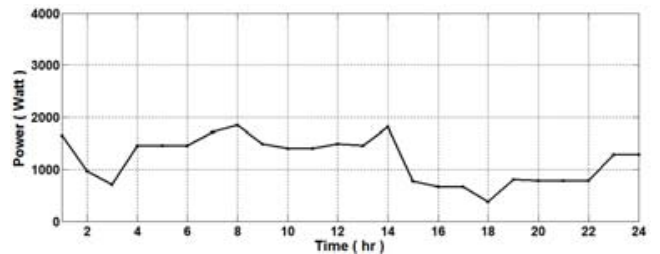

Fig.12 load curve after optimization

In Figure 12, sometimes load consumption at peaks must be shed to make safety operation to substation devices so the nodes where loads are high will be shed using optimization method, total power shedding after optimization=830 Watt

Total load consumption after load shedding $=28600 \mathrm{WH}$, Maximum power consumption will reduce from 2271 watt to 1841 watt at 2 am and load curve will be more smooth than load curve before optimization, So the reduction in power consumption using $\mathrm{BA}$ is around $2.8 \%$ of total power consumption per day. Total cost after load shedding $=7.625$ L.E/day.

\section{(IV) Control Action:}

After applied three methods to find the optimum load with suitable cost and compare results we found that:

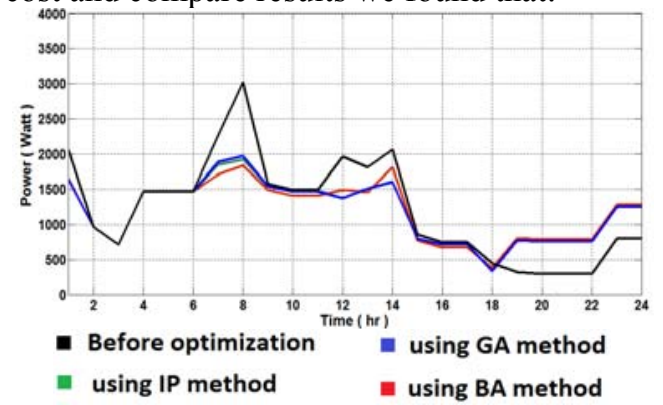

Fig.13. power consumption before and after optimization methods

Table (IV): Comparison between power consumption and cost IP, GA and BA optimization methods:

\begin{tabular}{|l|l|c|c|c|}
\hline \multicolumn{2}{|l|}{ Optimization method } & $\begin{array}{c}\text { Maximum } \\
\text { Consumption } \\
\text { in Watt }\end{array}$ & $\begin{array}{c}\text { Daily load } \\
\text { in WH }\end{array}$ & $\begin{array}{c}\text { Daily } \\
\text { cost in } \\
\text { L.E }\end{array}$ \\
\hline Before Optimization & 3015 & 29430 & 10.81 \\
\hline \multirow{2}{*}{ Interior point } & Shift & 2326 & 29430 & 8.53 \\
\cline { 2 - 5 } & Shed & 1923.8 & 28784 & 7.713 \\
\hline $\begin{array}{l}\text { Genetic } \\
\text { Algorithm }\end{array}$ & Shift & 2318.4 & 29430 & 8.3 \\
\cline { 2 - 5 } & Shed & 1968.4 & 28661 & 7.63 \\
\hline
\end{tabular}




\begin{tabular}{|c|l|c|c|c|}
\hline \multirow{2}{*}{ Bat Algorithm } & Shift & 2271 & 29430 & 8.23 \\
\cline { 2 - 5 } & Shed & 1841 & 28600 & 7.625 \\
\hline
\end{tabular}

From table (IV) it is noted that Bat algorithm has the lowest Maximum Power consumption point with the lowest cost. However that results using genetic and bat algorithms are approximately the same, but computation time in BA around $30 \%$ computation time in GA using MATLAB program.

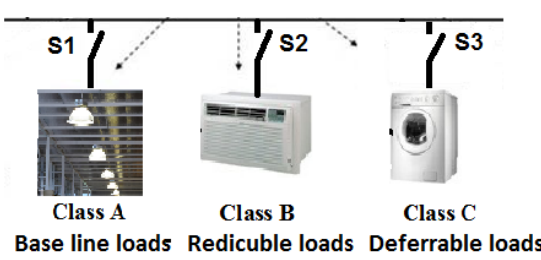

Fig.14. proposed system with control action

Load consumption in Class $\mathrm{A}=490$ watt, 4.27 ampere

Load consumption in Class $\mathrm{A}=1500$ watt, 6.82 ampere

Load consumption in Class $A=1460$ watt, 6.63 ampere

Table (V): Switches maneuver:

\begin{tabular}{|c|c|}
\hline Time & Control Action \\
\hline 8AM: 2PM & $\begin{array}{c}\text { S1, S2 are closed \& S3 is opened (Maximum load } \\
\text { consumption = 1990 watt, 9 ampere). }\end{array}$ \\
\hline 2PM: 8PM & $\begin{array}{c}\text { S1, S2 are closed \& S3 is opened (Maximum load } \\
\text { consumption = 1990 watt, 9 ampere). }\end{array}$ \\
\hline 8PM: 2AM & $\begin{array}{c}\text { S1, S3 are closed \& S2 is opened (Maximum load } \\
\text { consumption 1950= watt, 8.86 ampere). }\end{array}$ \\
\hline 2AM: 8AM & $\begin{array}{c}\text { S1, S3 are closed \& S2 is opened } \\
\text { (Maximum load consumption = 1950 watt, 8.86 } \\
\text { ampere). }\end{array}$ \\
\hline As power & consumption for one consumer $=$ \\
\hline
\end{tabular}

$960 \mathrm{KW} / 400$ consumer $=2400 \mathrm{Watt} / \mathrm{Day}$, so the maximum load consumption $=10.9$ ampere. The maximum load consumed after load optimization $=9$ ampere.

Total power consumption before optimization in month = $29430 * 30=882.9 \mathrm{KWH}$, Where the peak of load consumption $=3015$ Watt at $3 \mathrm{PM}$ and the total cost in month $=10.8 * 30=324$ L.E. Referred to Table (IV) calculations of power and cost using Bat algorithm, so the average consumption in month will be $=29430 * 30=882.9 \mathrm{KWH}$, But the peak of load consumption reduced to $=2271$ Watt at $3 \mathrm{PM}$ and cost in month $=8.23 * 30=246.9$ L.E for one consumer. If we have 10 buildings and the buildings have 40 consumers, each consumer will save minimum 77 L.E per month.

\section{CONCLUSION}

The paper presents a comprehensive study on a proposed smart DSM controller. The controller consists of two parts; a smart meter design using PLC and an optimized DSM technique. The proposed smart meter has the ability of two way communication between customer and utility central control which enables both customer and utility to take planned decision based on loading information.

The DSM techniques support both customer and utility decision regarding energy management especially during peak hours. The proposed DSM utilize bat optimization algorithm that gives the best load clipping and load shifting according to preset constraints of the utility. Proposed smart meter receives the optimized values and apply the control action on customer level to achieve the overall purpose of energy management of the whole system. The proposed DSM proves its ability to save more energy than regular DSM techniques. In addition the proposed smart meter gives the opportunity to measure, observe, and control customer individual appliances through central utility control which is a new concept for smart grid.

Customer saving in electricity price is also achieved taking into consideration different tariff for different operating hours. The proposed system proves controllability at different levels "customer's and utility's" with economic optimization.

\section{REFERENCES}

[1] Thillainathan Logenthiran, Dipti Srinivasan And Tan Zong Shun: "Demand Side Management In Smart Grid Using Heuristic Optimization", IEEE Transactions On Smart Grid, Vol. 3, No. 3, September 2012.

[2] George W. Arnold," Chapter 17 Smart Grid", National Institute of Standards and Technology, U.S, Springer-Verlag Berlin Heidelberg,2011.

[3] giuseppe tommaso costanzo, "demand side management in the smart grid", Diploma control of Applied Science (Electrical Engineering), canada,2011.

[4] M. N. Ullah, N. Javaid, I. Khan, A. Mahmood, M. U. Farooq, "Residential Energy Consumption Controlling Techniques to Enable Autonomous Demand Side Management in Future Smart Grid Communications", Eighth International Conference on Broadband, 2013.

[5] A. Abaza, Ahmed M. Azmy, "Demand-side management-based dynamic pricing within smart grid environment", Faculty of Engineering, Kafer elShiekh University, Tanta University, 2013.

[6] Italo Atzeni, Luis G. Ordóñez, Gesualdo Scutari, Daniel P. Palomar, and Javier Rodríguez Fonollosa, "Demand-Side Management via Distributed Energy Generation and Storage Optimization", JUNE 2013.

[7] Mohamed E. El-Hawary," The Smart Grid-State-of-the-art and Future Trends", Dalhousie University, Halifax, Nova Scotia, Canada, 2014.

[8] Zubair. M. Fadlullah, Minh. Q. Duong, Nei Kato, and Ivan Stojmenovic, "A Novel Game-based Demand Side Management Scheme for Smart Grid," IEEE Wireless Communications and Networking Conference (WCNC 2013), Shanghai, China, Apr. 2013.

[9] K. S. K. Weranga, Sisil Kumarawadu,D. P. Chandima, " Smart Metering Design and Applications ", Springer Singapore Heidelberg New York Dordrecht London, 2014.

[10] Phani Chavali, Peng Yang and Arye Nehorai, "A Distributed Algorithm of Appliance Scheduling for Home Energy Management System", IEEE Transactions On Smart Grid, Vol. 5, No. 1, January 2014.

[11] Savings Potential through Transparent Energy Flows, Energy Management in Low-Voltage Power Distribution, www.siemens.com/powermanagementsystem.

[12] Zafar Ali Khan, Saeed Ahmed, Rab Nawaz, Anzar Mahmood, Sohail Razzaq ,"Optimization based Individual and Cooperative DSM in Smart Grids: A Review", Department of Electrical Power Engineering, Mirpur AJK, Pakistan 1,2,3, EE, COMSATS Institute of Information Technology Islamabad, Pakistan4,5,2014.

[13] Mohamed Abo Galeela, Magdy El-Marsafawy, Mohamed El-Sobki, "Optimal Scheme with Load Forecasting for Demand Side Management (DSM) in Residential Areas", Electrical power and Machines department, Faculty of engineering Cairo University, Giza Egypt,2013.

[14] Kumaraguruparan N., Sivaramakrishnan H., and Sachin S. Sapatnekar, "Residential Task Scheduling Under Dynamic Pricing Using the Multiple Knapsack Method", University of Minnesota-Twin Cities, Minneapolis, MN 55455, IEEE PES Innovative Smart Grid Technologies (ISGT), 2012.

[15] IEEE POWER ENGINEERING SOCIETY, IEEE Node Test Feeder.

[16] Egyptian Electric utility and Consumer protection Regulatory Agency, www.egyptera.org.

[17] Yang Li, "An Efficient Demand-Side Load Shedding Algorithm In Smart Grid", A thesis submitted to the Department of Electrical \& Computer Engineering, Queen's University Kingston, Ontario, Canada, September, 2013.

[18] Arkadi S. Nemirovski, Michael J. Todd, " Interior point methods for optimization", Acta Numerica , pp. 191-234, Printed in the United Kingdom, Cambridge University Press, 2008.

[17] Yang Li, "An Efficient Demand-Side Load Shedding Algorithm In Smart Grid", A thesis submitted to the Department of Electrical \& Computer Engineering, Queen's University Kingston, Ontario, Canada, September, 2013. [19] Martin Hasaj, " Smart Home - Opportunity to make life easier ", Universtita Politecnina Du Catalunya,2008.

[20] Xin-She Yang, " A New Metaheuristic Bat-Inspired Algorithm " Department of Engineering, University of Cambridge, Trumpington Street, Cambridge CB2 1PZ, UK,2010.

[21] Xin-She Yang, Amir Hossein Gandomi, " Bat Algorithm: A Novel Approach for Global Engineering Optimization", Mathematics and Scientific Computing, National Physical Lab, Teddington TW11 0LW, UK, Department of Civil Engineering, The University of Akron, Akron, OH 44325, USA, 2012. [22] Mir Asif Iquebal, " Genetic Algorithms And Their Applications: An Overview", Ph.D. (Agricultural Statistics), Roll No. 9068 I.A.S.R.I., Library Avenue, New Delhi-110012. 